\title{
MUDANÇAS DE COMPORTAMENTO EM SAÚDE E SUAS BARREIRAS EM INDIVÍDUOS DA REGIÃO NOROESTE DO RS
}

Luma Stella Teichmann Bazzan; Programa de Pós-Graduação em Gerontologia, Universidade Federal de Santa Maria; luma_bazzan@hotmail.com

Daniela Paini; Nutricionista, Universidade Federal de Santa Maria; paini.dani@gmail.com Karoline de Oliveira dos Santos; Nutricionista, Universidade Federal de Santa Maria; kasantos98@hotmail.com Taane de Oliveira Aguirre; Nutricionista, Universidade Federal de Santa Maria; thayaguirre@gmail.com Adriane Cervi Blümke; Departamento de Alimentos e Nutrição, Universidade Federal de Santa Maria campus Palmeira das Missões; adriblumke@gmail.com Greisse Viero da Silva Leal; Departamento de Alimentos e Nutrição, Universidade Federal de Santa Maria campus Palmeira das Missões; greisse@hotmail.com

\section{RESUM0}

Introdução: A promoção da mudança de comportamento alimentar é uma boa estratégia para promoção de saúde e prevenção de doenças crônicas, porém, é um processo complexo, pois para que ocorra uma mudança significativa, o indivíduo deve ser motivado para o enfrentamento das barreiras e aprimoramento dos facilitadores para a mudança. Objetivo: Identificar a intenção de mudança de comportamento em saúde e possíveis barreiras em indivíduos adultos da região noroeste do Rio Grande do Sul. Métodos: Estudo transversal realizado à domicílio. Avaliou-se se os participantes achavam que deveriam fazer algo para melhorar a saúde; o que era mais importante mudar para melhorar a saúde; se existia algo que os impedia de mudar e se pretendiam mudar nos próximos 12 meses. Resultados: Foram entrevistados 139 adultos, com idade média de $42,53 \pm 12,2$ anos, $79,9 \%$ do sexo feminino. A maioria $(92,8 \%, \mathrm{n}=129)$ indicou que deveria fazer algo para melhorar a saúde, sendo mais importante fazer (ou aumentar) a atividade física (61,2\%, $\mathrm{n}=79$ ) e emagrecer $(19,3 \%, \mathrm{n}=25)$. As principais barreiras que os impediam de mudar foram falta de força de vontade $(36,4 \%, \mathrm{n}=47)$ e o horário de trabalho $(24 \%, \mathrm{n}=31)$. Nos próximos 12 meses pretendiam fazer (ou aumentar) exercício físico $(92,2 \%, \mathrm{n}=119)$ e melhorar hábitos alimentares (87,59\%, $\mathrm{n}=113)$. Conclusão: A maioria dos participantes estava no estágio de contemplação, considerando que precisavam fazer atividade física e emagrecer para melhorar sua saúde e que para isso deveriam praticar exercício físico e melhorar hábitos alimentares. Como barreiras estavam a falta de força de vontade e horário de trabalho.

Palavras-chave: Comportamento; Promoção da saúde; Prevenção de doenças; Doença crônica.

Agradecimentos: CNPq e CAPES. 